\section{WORKING BETWEEN TWO WORLDS: NEW ROLES FOR TRADITIONAL THAI DANCE AND DANCERS}

\section{Pornrat Damrhung ${ }^{1}$}

\begin{abstract}
Thailand's financial collapse and new constitution in 1997 brought issues of commercialization, education reform, and decentralization to the forefront of arts and culture. The paper focuses on three aspects of the current situation of the traditional arts and artists in Thailand.
\end{abstract}

First, the commercialized globalization of the arts has prompted some artists to create drama companies and theatre events woven through with Western themes and contemporary forms, but grounded in traditional Thai performance. Second, the new emphasis on arts education by Thailand's recent educational reforms has prompted the creation of new arts education programs that train local artists to adapt themselves to a changing world. Thirdly, some artists trained in traditional techniques, like Pradit Prasartthong and Pichet Klunchuen, work on intercultural projects within and outside Thailand, bringing in new approaches to presenting their work in storytelling and choreography, and new modes of teaching. These three aspects point to the array of ways that artists can use traditional arts in the contemporary scene and make rigid forms of traditional arts more flexible and

\footnotetext{
1 Associate Professor, Department of Drama, Faculty of Arts, Chulalongkorn University, Bangkok, Thailand.
}

exciting for today's audiences. These trends and pilot projects make greater use of traditional knowledge for today's communities, and better reflect the interests of these communities. They provide the groundwork of a new movement in Thai performance that can create new opportunities for traditional performers and performance.

\section{Introduction: two artists working between two worlds}

In Thailand, as in other parts of the world, it is common to distinguish the world of traditional singers and dancers from the world of those who perform in modern theatre. Like artists working elsewhere, however, some Thai artists familiar with the tools and aims of traditional performance and of modern theatre regularly contribute to both "worlds." They participate in, while challenging, the two commonly recognized worlds of performance, and they do so by working between these worlds. As a result, these kind of artists are able to add to both worlds of performance in interesting and important ways. This paper will consider two such artists working between two worlds of performance - Pradit Prasartthong and Pichet Klunchuen - as a way of considering how popular (for Pradit) and classical (for Pichet) traditions can enhance Thailand's performance culture, whether traditional or modern.

Since these two artists were not trained in Thailand's prestigious National School of Music and Dance (Wittayalai Natasilp), they remain marginal figures to Thailand's world of traditional performance, which centers itself on that institution and its correlates, the Fine Arts Department and the National Theatre. Nonetheless, to many young people in Thailand, as well as artists 
and audiences outside of the country, these two artists embody traditional Thai dance for the international world of performance. Thus, although artists and audiences in the USA, Europe, and Japan may know the two artists as exemplary traditional Thai performers, Thailand's traditional artists and their enthusiastic audiences barely recognize them. These two men show a new way of using traditional dance for the contemporary scene, and their activities point out a way for traditional artists to work between the two common worlds of performance in order to make a new place in the contemporary dance scene for Thailand's traditional arts.

A brief look at the two artists' performances in Thailand in the last few years suggests how they have been using their grounding in the traditional arts to reach out to new work and audiences. In January 2002, Pradit Prasartthong worked with Manuel Lugenhorst on the experimental intercultural project, Phaulcon. $^{2}$ In October of the same year, Pradit played Mephisto and Pichet played Faust in a musical staging of Faust, directed by Janaprakal Chandrueng, at Thailand's Second Music and Dance Festival, and again in November at the First

${ }^{2}$ Phaulcon is not part of Thai History. As a play, it gave a picture of the important role of diplomacy in the reign of King Narai of Thailand and the court of the Sun King, Louis XIV, of France. The play was performed twice with different episodes. In the first one, at the director's place in Chiangmai, it used many artists. Khun Pradit played Phaulcon, and the whole royal court of Thailand was played by rod puppets. The music was a mix of modern Thai and western orchestral music. The second version was performed at the Tadu Studio in Bangkok, with Don Chareun-ngam playing Phaulcon.
Bangkok Theatre Festival at Phra Arthit Road. ${ }^{3}$ Pradit also revived a world tour of Likay Apiwat, a contemporary Likay (popular opera) piece based on the life of Pridee Panomyong, who played a key role in Thailand's 1932 push toward democracy. Pichet performed a contemporary dance solo piece called Thepanom. At the Second Bangkok Theatre Festival in 2003, Pradit staged a modern political Likay, the Conqueror of Ten Directions, ${ }^{4}$ that criticized Thai politics and politicians. Later Pichet also directed his own performance of Dependent Origination (Atipattajayata), using members from his new company, Lifework. $^{5}$

Besides staging these performances in Thailand, the two artists have also participated in international and intercultural projects during the last few years. Pichet was selected to play in the

\footnotetext{
${ }^{3}$ Faust was adapted and directed by Janaprakal Chandrueng. The play was in the style of a kind of traditional Thai performing art called Likay, the script of which was written by Pradit Prasartthong. It was also a play within a play. (from an interview with Janaprakal Chandrueng, Pradit Prasartthong and Pichet Klunchuen, November 2002).
}

${ }^{4}$ The Conqueror of Ten Directions is a novel based on Myanmar history in the time of King Bayingnaung, who conquered Ayudhaya in the seventeenth century. It became a hit and was adapted into dance drama performed by the Fine Arts Department (from an interview with Pradit Prasartthong, November 2003).

${ }^{5}$ Atipatjayata dealt with Buddhist philosophy, and tied it to the story of a woman who committed suicide. The choreography included mask-dance techniques performed with a live Piphat (a Thai classical music instrument) and piano improvisation (from an interview with Pichet Klunchuen and Sinnapa Sarasas, composer of the music used in the project, January 2004). 
Singapore director Ong Ken Seng's "Search Hamlet" in Denmark and also toured with the Theatre Works production of Ong's "Global Soul" in Europe and Asia. Pradit was invited to again play the lead in "Red Demon" (Akaoni), an intercultural project sponsored and run by the Japan Foundation, and he was also asked to lead workshops for community performances using traditional arts in China and Japan. He was later involved in a Mekong subregion project on the theme of rice culture with other Southeast Asian artists. To judge from their booking for current and future projects, the two artists will be involved in international projects for at least the next several years.

Through their work in Thailand and abroad, these two artists are helping write a new chapter in the life of traditional Thai dance. Although not accepted as part of the world of traditional performance in Thailand, the two use their knowledge of the traditional arts to create new works that attract Thailand's younger audiences, and that showcase Thailand's traditional arts in the world of international artists and audiences. In so doing, they have become leaders in training new performers and in attracting new audiences to the untapped possibilities available in Thailand's traditional arts.

\section{The cultural evolution of modern Thailand's traditional performing arts}

The new work being done by Pradit and Pichet is part of a long legacy of experimenting with Thailand's traditional performing arts, rooted in a deep history of working between cultures to create hybrid forms of traditional dance and dance-drama. Indeed, it points to something basic in the cultural evolution of not just Thailand but of Southeast Asia more generally. Thailand's diverse types of performance have drawn on a vast, open repertoire of stories, music, characters, motifs, and beliefs that have both local and foreign sources. For several centuries before 1932, the Thai royal court periodically selected, organized, and refined parts of this open archive into discrete traditions for its cultural enhancement, and has occasionally refreshed performance art by adding or modifying new elements from this vast open repertoire. At the same time, local communities have drawn on the same repertoire to fashion traditions that were valuable to its patrons and audiences, and were willing to change them as local tastes and aims changed. The open diversity of Thailand's performance cultures, with deep roots in both royal court and local communities, is something that all who travel in Thailand know about.

Reviving the classical arts was central to the consolidation of the current Chakri dynasty when it began more than two centuries ago. Under royal patronage, art forms were reinstituted and canonized. This patronage ensured that the classical arts would be part of a court culture that could celebrate the king's absolute power (in the case of Lakhon Nai [court dance]) or that could support the greatness of the king and his royal family (in the case of Khon [masked dance-drama]). Thus, since the late eighteenth century, key members of the royal family recreated classical dance theatre traditions for other noblemen and noblewomen, including the kings Rama II and Rama V, and Prince Naritsaranuwattibong. ${ }^{6}$ Until the late

\footnotetext{
${ }^{6}$ In the reign of King Rama $\mathrm{V}$, classical dance and music was run by the Krom Mahorsop (Department of Entertainment), which was under the Ministry of Education. See Mattani
} 
nineteenth century, however, women dancers in the court trained the new classical dancers. This permitted them to introduce new forms of musical play and helped to create new elaborate styles. King Rama VI and Prince Narathip Prabanbongs furthered the royal involvement with classical dance drama by using elements of Western theatre to produce many new forms of drama. ${ }^{7}$

Other forms of performance outside the court -Lakhon Chatri, Lakhon-Nork, Likay and Nohra assumed an array of roles. Besides entertaining audiences, these performances taught communities about morality and proper family life, while simultaneously using humor and doubleentendre to express socially unacceptable ideas and to mock the nobility. Some pious families or individuals would pay dance troupes for small-scale dance-offerings to thank the gods for aiding or blessing them. Since few ordinary people had enough resources to sponsor performances, support thus, typically came from either wealthy landowners or those connected to the court. Their contacts and interests in foreign things started to show up in new performance genres and pieces which they used to showcase their new cultural interests. The new foreign elements were adapted into Thai tastes and sensibilities. By the early twentieth century, therefore, wealthy noblemen, and merchants all sponsored elaborate performances in urban and rural areas, and these performances combined older native and more recent foreign elements onstage. Some dancers who had worked in the court, meanwhile,

Runin, Dance, Dance-Drama and Theatre in Thailand. Silkworm Books, Bangkok: 1997.

${ }^{7}$ Operetta and Spoken Theatre were introduced into the court and for noble audiences. worked outside for these new sponsors and audiences, and new hybrid dance forms were emerging.

This change in the sponsorship of performance helped to restructure the whole of Thai society and to create both a new and expandable repertoire of works for the stage. Although the royal court was still an important center of the high refined performance traditions and local communities still were regularly promoting less refined forms of religiously and culturally significant performance, rich merchants became new patrons for more exciting intercultural works.

After the end of absolute monarchy in 1932, the new parliamentary government took control over classical traditions, structuring them with a new bureaucratic agency called the Fine Arts Department (FAD). By the 1940 s, the dislodged royal dancers had established a curriculum and repertoire of classical genres for the FAD, and the government recast the royal arts in a nationalist mold, making them sources of Thailand's unique cultural identity. In claiming to be guardians of Thailand's cultural essence, government-run arts schools have also included the teaching and performance of some other significant forms of traditional arts that were not as central to the court earlier in the Chakri Dynasty, such as Lakhon Nork, even though these forms remain popular forms that thrive without state patronage.

The National Academy of Music and Dance system of training and performance has changed little in the last half century, while Thailand's social, economic, political, and cultural structures and priorities have changed markedly. Moreover, not all of traditional Thai culture has been claimed by the state. Mandatory 
education for all children has severely limited how much and what types of classical training are possible, even as new media such as radio, film, television, and later cassettes, videos, CDs, and now DVDs have expanded everyone's exposure to cultural productions. These two processes have combined, during the last few decades, to diminish the cultural place and vitality of the classical arts in contemporary Thailand. Several of the popular styles of performance, meanwhile, have learned to do very well without government sponsorship, mainly by blending their activities into commercial and entertainment businesses. ${ }^{8}$

\section{The situation of academic dance and music}

Thailand's traditional arts are thus bound up with changes in the Thai government, society and culture. They have prospered and suffered within uneven accelerations in the pattern of social, economic and cultural change in the last few decades. In this period, regional political concerns brought in new and more extensive forms of Western business and culture, and produced new forms of socio-political churning that expressed themselves in several coups d'etats, unprecedented forms of youth culture, and the standardization of the mass media. The dilemmas of becoming modern (still often interpreted as becoming "Western") while remaining Thai were accompanied by ideals of a quick materialistic accumulation of goods and services. As a

\footnotetext{
${ }^{8}$ In 1942, under the regime of Pibunsongkram, the standards for Dance and Performing Arts in Thailand were set. The law affected local performers, discouraging them from continuing their art forms.
}

result, a new type of cosmopolitan Thai culture emerged, especially in Bangkok. This culture has been shaped more by modern, Western ideals of arts and culture, and ignored many gaps between what Western arts do and their cultural foundations in Thailand. As corporations seeking to sell a fresh and lively Western civilization joined with the new powers of broadcasting culture via mass media technologies, they helped to feed the changes in Thai views.

Despite these significant socio-economic and cultural changes, the FAD and its Academy of Music and Dance have held a virtual monopoly on training traditional artists and teachers. To strengthen their hold on Thailand's classical culture, they expanded their curriculum and activities to twelve training academies for special students around the country. This expansion has helped the FAD to reinforce a standard curriculum and repertoire, and to ensure that the numbers and the quality of students with training in the classical arts keeps growing. This would be a good thing, except for the fact that those people lack much hope of using all their artistic training, since few of them can find much of a career path where they will be able to use it.

The institutional divisions into classical, folk, and modern theatre in Thailandestablished by the government and solidified by academic research-is matched by a hierarchy of respect for the arts. Immersed in mass media culture from a very young age, most young people are unmoved by the power and the value of disciplined training in the classical and folk arts. There is slightly more respect (and hope) for those interested in modern drama school, because they could work in television, advertising and film. The sharp 
institutional divisions are not helpful for young people who want to interact and learn from each other, communicate with each other, and reach their audiences. The current practices, systems and policies do not encourage pathways that lead to creating new products, markets and avenues for artistic collaboration in society.

The FAD is reluctant to respond to Thailand's rapid transformations. In this government organization, educational degrees and bureaucratic rank carry more weight than artistic innovation and intercultural exchange by artists and teachers. The Academy of Music and Dance has scarcely altered its fixed curriculum and repertoire. Moreover, there are no significant alternative training institutes or performance groups in the classical arts. Because of their guaranteed government support, the Academy and FAD have not felt the necessary competitive pressure to change their ways like art forms that have had to face real socio-economic pressures. Young graduates from the regional academies of music and dance can hope to sing and dance for tourists or to become teachers to serve in schools and communities, but these activities do not make full use of the many years of artistic training in dance and music. Thailand thus has a small and weak community of professional traditional artists. The survival of the traditional arts as a creative and innovative endeavor is questionable if the current approach is maintained. The traditional arts have been frozen in the minds of audiences as much as in the minds of the mentioned performers.

This new environment for the traditional arts and artists has meant the emergence of new official roles for the arts and the classical arts as the embodiment of Thai culture for young people and foreigners. By setting firm standards of beauty and a limited repertoire of performances, there is also a limit set to what counts as culture. These limitations have led to an official discounting and a discrediting of much of the rich diversity of our performance traditions. With a less diverse spectrum of art forms and traditions officially recognized by the state, they became separate from the community and from the school curriculum. A highly centralized education system produced a standardized form of beauty set by the FAD - itself a branch of the Ministry of Education-and this has led most communities to undercut their local folk arts and artists, and diminish their place in the local community. ${ }^{9}$ This situation has prevented people from gaining maximal benefits from their local arts and artists. To survive, many of the local artists adjusted themselves to the new public tastes and linked their arts with modern entertainment from the mass media. Some other arts and artists tied themselves into the spiritual needs of their local communities. ${ }^{10}$ Not surprisingly, those with ties to the commercial mass media have been better able to adjust and thrive than those assuming ritual purposes.

With the slow implementation of the constitution since 1997, and especially

\footnotetext{
${ }^{9}$ The Wittayalai Natasilp, or National Academy of Dance, has gradually developed branches in provinces around the country. During the last decade, the Departments of Dance in two universities, Chulalongkorn and Srinakarintraviroj, have begun teaching Thai dance for a BFA degree.

${ }^{10}$ S. Pattrachai, P. Damrhung, et al., Folk Dance Drama: Adjustment to Modernization. Research study for Thai Studies Institute, Chulalongkorn University.
} 
since the new government and the educational reforms from 2002, these trends seem to be reversing. Part of the decentralization efforts promoted by the government, largely as a result of the 1997 monetary and fiscal collapse and the bailout accord achieved with international financial institutions, has helped to make classical and popular theatre traditions more diverse and differentiated. This kind of trend encourages performing arts organizations to develop new missions that reach and move their local audiences, thus gaining their support.

\section{Thai performance culture outside the Fine Arts department}

Many people see the unique and exotic "Wong" (the circling of the arms) and "Jeep" (symbolic hand gestures) as central to Thai classical dance. That was not always the case. These features only became markers of Thai dance after classical schools produced a fixed curriculum around sixty years ago, mainly to permit young adults to learn a standardized program of classical Thai art. Although first fixed into a 12-year plus 4year program, after which successful candidates received a certificate and degree, the program was later reduced and focused. All of this standardization and regulation has shrunk the scope for creativity and simplified the complexities that were once central to Thai dance and dance theatre. ${ }^{11}$

11 The Pattanasilpa Institute, operated by the Academy of Music and Dance, offers a Degree Program that allows students to create traditional and new forms of dance that are based on classical techniques. Other universities that offer bachelor degrees in Dance and Music are the School of Fine and Applied Arts at Chulalongkorn University, the School of Fine Arts at Srinakarintraviroj University, the Rajmonkol Institute, and the University of
Since most popular forms of dance lacked the status of the old court-based forms, they received no or only very low levels of government support. They thus were faced with a choice of either adapting to the changing socio-cultural environment outside of the government or perishing. Those dance-forms whose artists chose the path to survival depended on the artists' creative ways of creating a niche for their work in a consumer- and commerciallydriven environment. Other forms are now part of history.

There have been many changes in the training of traditional dance in Thailand. The pressure of new values, such as getting a government-certified degree from the educational system now push artists to set up post-secondary higher degree schools for the artists to equip the artist-students with the possibility of a new career as a teacher and sometimes as professional artists .

The shorter period of the classical dance training curriculum and the limited time one is able to work effectively as a dancerteacher in the new school system have made the Thai classical dance curriculum into a package and a form to be studied and imitated more than a lifelong training regime that required a lot of performance experience.

As new social values, rooted in modern technology and entertainment, have become more important, classical dance has frozen its repertoire, performing in the public arena mainly for foreigners interested in exotic performances or for school-age children asked to learn something about their cultural past. The forms of teaching

Rajabat (formerly Thailand's 36 teachers' colleges). 
and learning classical dance need to find ways to create new versions of classical productions that can attract a larger and more informed audience. Some changes have occurred with classical dance in the popular mode, such as Khon (masked dance) done with lasers and modern sets. ${ }^{12}$ Others have used new choreography and new text to rework performances. ${ }^{13}$ New stage technologies have also been employed for standard performances, and some performances have worked by juxtaposing different genres of dance and music onstage simultaneously.

Attempts to juxtapose Thai and Western dance forms started at least thirty years ago and continue into the present. Ballet and classical Thai dancers appear onstage doing what they do best, sometimes using some spoken theatre and traditional dance, or story theatre with Thai classical dance and music. These are now familiar to if not always accepted by Thai audiences. These and other formats have used classical dance and dancers onstage in university productions and in private venues as part of contemporary Thai performance for at least three decades. Likewise, folk dance and singing have adapted themselves into the popular entertainment business, as show concerts by young Likay performers or in a Morlum concert that we call "Morlum Cing."

${ }^{12}$ This was done at the Chalermkrung Theatre and was created and directed by artists of the Fine Arts Department.

13 The Patravadi Theatre presented khon performances that used shadow puppets in their performance of "Sahatsadecha," which has also toured schools. It was a very modern and creative production, and touching to young audiences. The story moved quickly and used shadow puppets to help tell the story.
Consumerism and entertainment businesses have begun to swallow up many new artists from traditional schools, thereby helping to make the goal of gaining money more important than the goal of making fine art. By packaging traditional forms of performance art in this way, for distribution by entertainment companies and by the tourism department of our government, innovative (if not always excellent) performance styles have begun to emerge. These new forms of dance and shows have tended to focus on entertaining new audiences in Thailand. When artists have begun to work with international choreographers and directors, some aspects of the traditional arts have become known on the international stage.

\section{Making intercultural performance: traditional arts for today's stage}

What is intercultural performance in Thailand? As I hinted at above, I see intercultural exchange as central to all art forms in Southeast Asia, including those in Thailand. Peoples in this part of the world have been absorbing forms and elements from foreign lands such as those in South and East Asia, incorporating some local elements to create coherent artistic traditions, and modifying them through further exchanges with other regional and global cultures. The various artistic forms and traditions now embedded in many of Southeast Asia's educational or cultural ministries as one or another type of "national art" are, in this view, just the cultural precipitates of a long and ongoing web of intercultural exchanges. For centuries, artists and cultural workers have worked in the intercultural performing arts mode, and have regularly adapted various forms into the various art forms now integral to the identity of each country. 
Despite being part of this older system of exchanges, artists and audiences alive today are now living in a world where supraregional forms of localized intercultural performance have reached a higher profile in the international world of contemporary performance. This is the world of cultural globalization.

To me, intercultural work means artists creating interactive forms with two or more cultural forms on the same stage or in the same performance. It aims, in other words, at creating something that might be quite different from the original forms. Intercultural performance mixes different cultural ideas, styles, and motifs in order to produce a single new artistic thing. For Thai society, intercultural work may benefit from the interplay among old traditional and newer forms in order to serve each particular audience of the old forms and to create new local audiences.

Compared to some of its Southeast Asian neighbors, Thailand is more open to the world through various foreign media, and has been that way for several decades. This openness has allowed many Thais to familiarize themselves with more of the global artistic reference points and to become more aware of different points of view, but it has also helped to hypnotize large segments of the population into seeing highly edited and technologically enhanced performances as the hallmarks of cultural success. Moreover, many of these altered performances are valued by their resemblance to global icons and by their commercial success. Such changes in audience expectations have made it hard for the poorly sponsored forms of traditional dance performed live and for individual or group performance skills to find a space, not just in the media, but also in live venues.
If we look at the traditional arts in Thailand, most of the popular forms that are still strong are those that have adapted themselves to commercial entertainment. Most of the local traditions that followed less-disciplined forms have adapted their art forms and management styles to the tastes local audiences have come to expect from their TV or video watching. Likay performers and Morlum singers are promoted by audio companies and give live shows more as live concerts with a storyline rather than in traditional formats. They are also often promoted as singers, and get most of thier income from audio VCD and DVD sales.

One popular form that has survived with many traditional features is Lakhon Chatri, and Norah, which have been able to find a place in local communities as ritual dances performed for spirits and for thanking the gods. The forms maintain their oldfashioned beauty, but have slowly-but unevenly-changed from ritual performances for the gods to performances for human audiences.

It is also difficult for Thai audiences who classify their traditional arts into the frozen museum pieces (classical arts) or the new commercially-driven entertainment forms (popular entertainment). They are not able to easily understand or appreciate new codes and new ideas springing from contemporary artists. It has been hard to accept that the traditional arts also have their own timing and functioning in society. To go beyond preserving these forms, will mean making use of a lot of new management techniques and a stronger effort to find a place in today's more complicated cultural world. 


\section{Traditional arts and artists for today's world: Pradit and Pichet}

The training of traditional dancers in Thailand has changed in recent decades. New social and cultural values, such as getting an educational degree, have encouraged the emergence of higher degree schools for artists and helped to equip the artist-students for new careers as teachers and professional artists.

As the length of training traditional artists in state-run schools has shrunk and as the traditional arts have become a smaller part of the general arts curriculum, Thailand's classical dance curriculum has become more of a package of study that stresses copying form more than it does a lifetime form of training shaped by live performances. As society has changed, new values tied to modern technology and entertainment have forced classical dance to freeze their forms and repertoire, and shrunk their place in the public space.

Today's trends toward consumerism and the entertainment business have opened up younger artists from traditional schools to both traditional training and business thinking. The new packaging of live entertainment by music companies and television and by government tourism agencies has shaped new forms of dance and performance that entertain new audiences locally and internationally.

Despite being marginal players to the world of Thai traditional dance, traditional artists such as Pradit Prasartthong and Pichet Klunchuen are significant for their innovative art and their innovative teaching. They are well-placed to become new masters for the next generation of performers and to help shape a new array of possibilities for the traditional arts for
Thailand. Several reasons underlie this. Firstly, the two have had different educations. ${ }^{14}$ Both have got their bachelor degrees and have not been trained in the strict conventional Academies of Music and Dance and the nationalized training system. Secondly, both have had special training with top masters in traditional forms, and this special training has given them distinctive knowledge of an art which most other students fail to get. Pradit trained in the Male Role with the National Artist, Mae Khru Suwannee Chalanukror, and Pichet was the only private student of Por Khru Chaiyot Khumanee, a renowned dancer in the Giant role. Thirdly, both have worked in modern theatre. Pradit has led a mobile theatre company for two decades which has long used traditional arts, motifs, and stories to present works to rural and international audiences. Pichet trained in modern theatre with the Department of Dramatic Arts at Chulalongkorn University and in the New Heritage Theatre Company for two years. Fourthly, both have had long experience in working with Thai and foreign contemporary dancers and artists in Thailand and abroad, such as: Bruce Gaston, Ong Ken Seng, Pattravadi Meechuthon, Janaprakan Chundrueng, Hans Hoenicke, Linda Hardy, Sinnapa Sarasas, Leon Rubin, Katsura Kan, Vararom Patchimsawadi, and Pornrat Damrhung. Finally, both can communicate their art and dance with foreign artists, and both can think and choreograph beyond the traditional mode.

It has been easier for Pradit to work and communicate with others because he has worked with other artists for a much longer time and is more familiar with the traditional arts. He has struggled more and has given his art a new character with his

14 Pradit graduated from the Department of Sociology at Thammasat University. Pichet graduated from the Faculty of Fine and Applied Arts at Chulalongkorn University. 
mastery of the popular form of Likay (which is popular and freer than the classical arts). This has given him more ability to interact and respond with different kinds of people.

Pradit Prasartthong also trained in Khon and in the male protagonist role in Classical Dance in his youth. After completing his university degree, however, he decided to work for young people. It took him a decade to become interested in traditional forms of the arts and use them as the basis of his touring theatre company. It took another decade for him to be able to master this art. His urban Likay performance was clever, beautiful, and sharply sarcastic about many aspects of Thai society. It made the middle class audience laugh. It thus represents the knowledge of educated middle classes in Bangkok rather than the rural audiences that had a secondary school education or less.

Pichet's classical dance is quite conventional in the sense that he has spent much time in disciplined refining and searching within the classical art form and the artist himself for the right combination of tradition and innovation to communicate his deep and nuanced emotions. That has led him to a more profound and refined style of classical dance, but he has also experienced a difficult time surviving and struggling in order to present his work and get audiences to understand and appreciate his new traditional dance form - minus all the Jeep and Wong that Thai audiences are used to.

Pichet has been more isolated and individual in both his training and in his work. He was the only Khon dancer who had studied with his Master in private classes for several years in the old style training. $\mathrm{He}$ was quite famous internationally and had more study within the training - the body structure and the balance and techniques of Thai dance. His international experience had made him more of a solo performer and it was more difficult for general audiences to understand his new code although elaborated from Thai classical dance. All of his performances are strong, energetic, beautiful, and sharp, but also very demanding on the audience who has to pay close attention. His work is stunning and exciting, but it might not lead to easy communication.

\section{Concluding remarks}

This article has briefly situated the contemporary work of two traditional artists in Thailand's changing society and culture. Many other interesting and important traditional artists besides this pair also use their knowledge for the contemporary stage. However, most of these other artists have stayed in Thailand without gaining much international experience, so their greatest influence has been on Thailand's classical dance and on young Thai trainees in classical dance. ${ }^{15}$ What distinguishes former two and some others is that they productively work on the margins between the traditional world and the modern world of performance. They

15 Several others of importance are Master Julachart Arunyanark and Chanchai Harnarong, part of a new generation at the Academy of Music and Dance (graduates from the new Institute of Pattanasilp, operating under the Ministry of Culture). Other artists with traditional training who are struggling to find a place in Thai society include the New Dance Company, headed by a young female dancer and choreographer, Siriluk Songklip, and the Komalagul Troupe, run by Chanchai Hanarong and friends from the Academy. 
have not only worked abroad more, but they have also begun teaching a new generation of artists, thus helping to blaze a new trail in Thai contemporary performance using traditional techniques.

Neither of the artists considered here are part of the world of Thailand's traditional dance. Neither of them has trained or worked in Thailand's National Academy of Music and Dance, and neither is considered to be a traditional dance teacher. Both, however, learned the traditional arts in unconventional ways, and this mode of learning has allowed them to develop unique styles and to be more creative with their use of traditional dance-drama. Working between the world of official dance-drama and the world of international performance, the two resemble the artists of a century ago who struggled to make a living with their art outside the court in the new commercialized urban culture shaped by foreign influences. In both cases, their traditional training serves as a foundation for their experimental work and teaching methods, while they make extensive use of a variety of modern, non-traditional, and foreign sources of inspiration and sponsorship. Today, there are very few opportunities for an artist who has not trained in the National Academy, no matter the skills and training, to make a living. The way these two have chosen is to work between the traditional and modern worlds of performance.

Yet the two artists considered are working between these worlds in very different ways, and trying to reach today's audiences differently, too. Pradit Prasartthong's work attracts mainly urban, university-educated audiences who can appreciate his funny political contemporary Likay, while Pichet Klunchuen is still struggling to find a consistent audience base for his modern performance grounded in old dance techniques and using many ideas from Buddhist thought. Pradit tends to address relevant issues using familiar forms, such as in his "Likay Apiwat," which deals with the prospects of democracy in Thailand. Pichet, meanwhile, tends to create works that speak different languages that seem very non-Thai but retain the heart of Thai performance. Both artists remain actively involved in creating new roles for traditional Dance and Dance Theatre that speak to the present day audiences so that traditional dance can work outside of exotic traditionalism, and outside of the mainstream arts, too. To date, they have mainly worked outside of and independent of government support.

This situation may change. Thailand's new Ministry of Culture includes a division for contemporary arts, and its first director aims to support contemporary work that uses traditional arts. ${ }^{16}$ Such government support will allow such artists to gain recognition not just for their performances, but also to train new artists and for creating new forms of art that serve modern audiences while retaining the stamp of Thai traditional arts. The two different men would be two good people to help set out a new vision for traditional arts, since both are concerned with fundamental aspects of lengthy training and the heart of the dance for today's audiences. Although strong in their own disciplines and traditions, they are also eager and able to communicate with young people and those not so familiar

16 Dr. Apinand Posayanond, a world-famous curator, was named to this position. This is the first time that the contemporary arts have gained a place in government thinking and planning about the arts. It suggests that they are now accepted as an independent category of the arts in a national organization. 
with the complex nuances of classical art. They want to show the necessity of their particular dance training, thus helping them to train new people for working in contemporary dance. They are a new kind of teacher and also a new kind of choreographer who have seen and worked with the best artists in both Thailand and in international settings. This allows them to see their place in the world more clearly and to help to bring international standards and expectations back to Thai audiences and performers. Perhaps this new support can help to enrich the work being done between the traditional and the modern worlds of performance.

\section{References}

Chua Soo Pong. (ed.). 1995. Traditional Theatre in Southeast Asia. Singapore: SEAMEO-SPAFA.

Don Rubin and Carlos Solorzano. (ed.). 1998-2001. The World encyclopedia of contemporary theatre. London and New York: Routledge.

Mattini Rutnin. 1997. Dance, DanceDrama and Theatre in Thailand: the process of development and modernization. Bangkok: Silkworm Books.

Pavis Patrice. 1990. Le theatre au croisement des cultures. Paris: Jose Corti.

S.Pattrachai and P.Damrhung. (et.al.). Folk Dance Drama: Adjustment to Modernization. Research study for Thai Studies Institute. Bangkok: Chulalongkorn University.

\section{Illustrations}

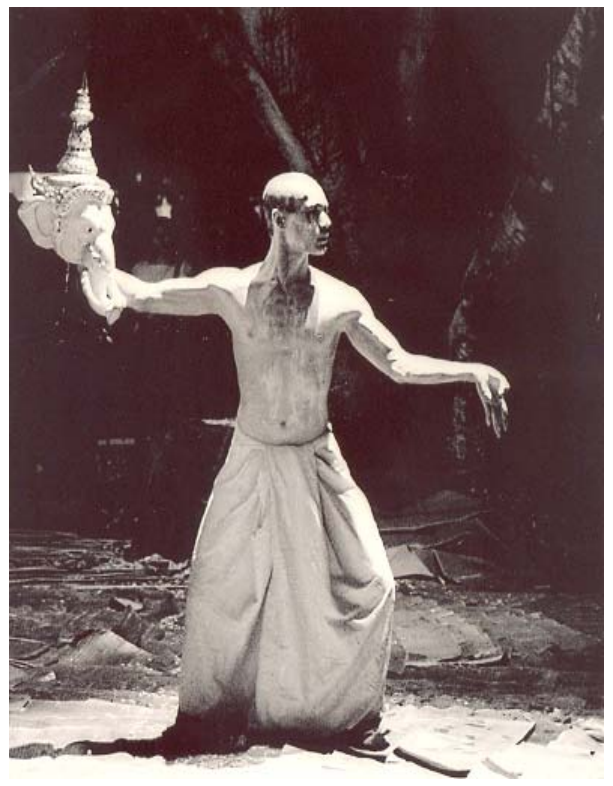

Pichet Klunchuen in his world tour of PyaChatthan. A dance performance of Buddhist Jakata.

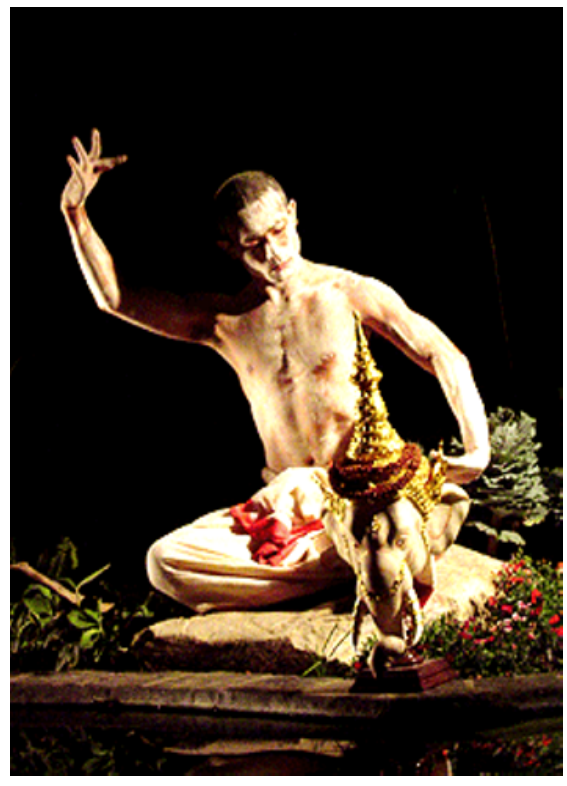

Pichet Klunchuen in his world tour of PyaChatthan. A dance performance of Buddhist Jakata. 
Working Between Two Worlds: New Roles for Traditional Thai Dance and Dancers

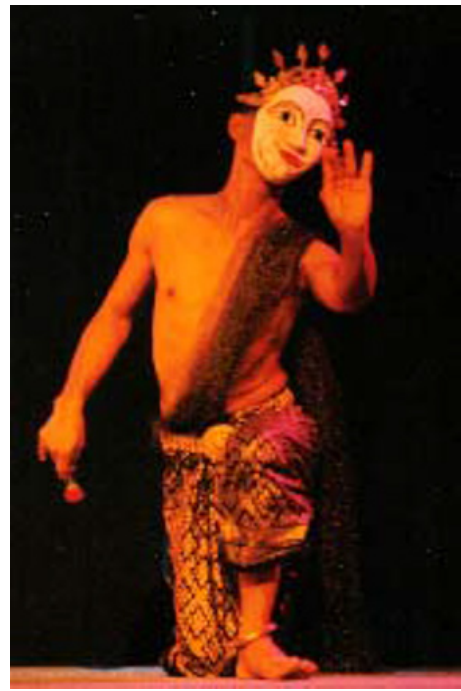

Pradit Prasartthong in "It could be nice in heaven"

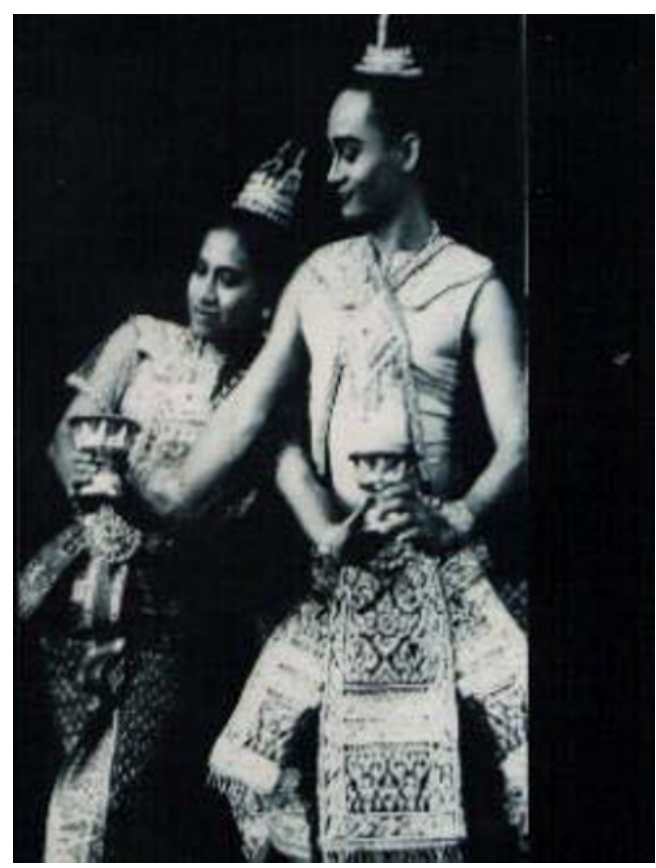

Pradit Prasartthong and Pongjit Suppukun in Pitsathan uey. A Dance tour in England and Australia.

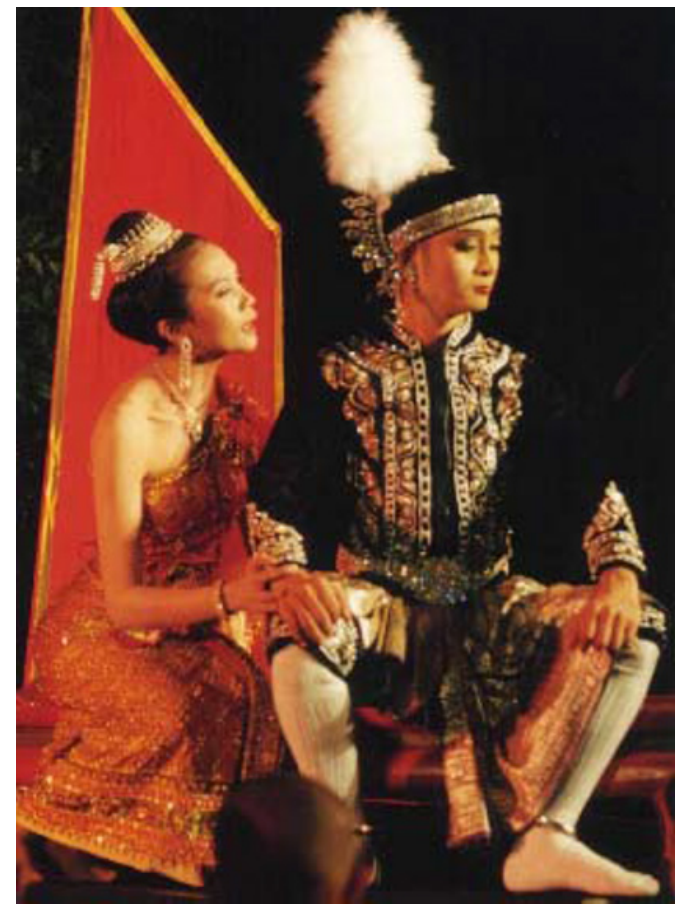

Pradit Prasartthong and Duangkhae Buaprathon in Likay-Apiwat- urban Likay about democracy in Thailand. Likay tour in Australia. 